\title{
Barriers to accessing weight-loss interventions for patients with class II or III obesity in primary care: a qualitative study
}

\author{
Boris Zevin MD PhD, Nancy Dalgarno PhD, Mary Martin MSc, Colleen Grady DBA, \\ Jacob Matusinec MD, Robyn Houlden MD, Richard Birtwhistle MD MSc, Karen Smith MD, \\ Rachael Morkem MSc, David Barber MD
}

\section{Abstract}

Background: Over 1 million Canadians have class II or III obesity; however, access to weight-loss interventions for these patients remains limited. The purpose of our study was to identify the barriers to accessing medical and surgical weight-loss interventions from the perspectives of 3 groups: family physicians, patients who were referred for weight-loss intervention and patients who were not referred for weight-loss intervention.

Methods: Between November 2017 and May 2018, we conducted a qualitative exploratory research study using focus groups with family physicians and interviews with patients with class II or III obesity from 1 region in southern Ontario. We conducted a thematic analysis to identify emergent themes and used the barriers to change theory to classify the similarities and differences between the perspectives of family physicians, referred patients and nonreferred patients in first- and second-order barriers.

Results: Seventeen family physicians participated in 7 focus groups (1-4 participants/group), and we interviewed 8 referred patients and 7 nonreferred patients. We identified lack of resource supports, logistics and lack of knowledge about weight-loss interventions as first-order barriers to change, and lack of knowledge about root causes of obesity, lack of patient readiness for change and family physicians' perceptions about surgical weight loss as second-order barriers to change. Family physicians and patients had similar perceptions regarding lack of resource supports in the community, logistical issues, family physicians' lack of knowledge regarding weight-loss interventions, patients' lack of motivation and family physicians' perceptions of bariatric surgery as being high risk. They differed regarding the root cause of obesity, with family physicians attributing obesity to multiple extrinsic and intrinsic causes, whereas patients believed obesity was largely due to intrinsic causes alone.

Interpretation: It is important to address first- and second-order barriers to accessing weight-loss interventions through continuing professional development activities for family physicians to help ensure effective and timely treatment for patients with class II or III obesity and related comorbidities.

besity is a chronic, progressive disease that is difficult to treat and is associated with many detrimental health effects. ${ }^{1}$ Sustained weight loss is associated with prevention, alleviation and resolution of many obesityrelated comorbidities. ${ }^{2}$ Weight-loss interventions such as medical weight loss (including behaviour intervention, medically supervised weight management programs and antiobesity medications) and bariatric surgery are available to some Canadians with class II (body mass index 35.0-39.9) and III (body mass index $\geq 40$ ) obesity through provincial insurance programs. ${ }^{3}$

Although this is the case in Ontario, there are barriers to accessing these interventions. Out-of-pocket cost for meal replacements and lack of insurance coverage for antiobesity medications are barriers to medical weight-loss interven- tions. ${ }^{4}$ Wait times, insurance and funding issues, and gaps in physicians' knowledge are barriers to accessing bariatric surgery. ${ }^{5,6}$ In 2017 , bariatric surgery was offered to less than $1 \%$ (1 in 178) of eligible Canadian adults. ${ }^{4}$ Less than $50 \%$ of physicians feel comfortable explaining bariatric surgery to

Competing interests: All of the authors report a grant from Medtronic during the conduct of the study. Boris Zevin also holds an educational grant from Ethicon.

This article has been peer reviewed.

Correspondence to: David Barber, david.barber@dfm.queensu.ca CMAJ Open 2019. DOI:10.9778/cmajo.20190072 
patients, discussing what occurs during the referral process and surgery, and identifying risks and benefits of contemporary bariatric surgery. ${ }^{7,8}$

Although barriers to accessing weight-loss interventions have been identified, ${ }^{4-8}$ the barriers from the perspectives of family physicians and patients with class II or III obesity in Canada remain underexplored. The purpose of our study was to identify the barriers to accessing weight-loss interventions from the perspectives of family physicians, patients referred for a weight-loss intervention and patients who were eligible but were not referred for such an intervention.

\section{Theoretical framework}

Our paper is framed by the barriers to change theory. ${ }^{9-11}$ First-order barriers to change are extrinsic and occur outside the change agent's control. They include lack of resources, ineffective professional development and training, and inadequate supports. ${ }^{12-15}$ Second-order barriers are intrinsic and involve changes to practice and beliefs. They are viewed as less tangible, deeply rooted and more personal than firstorder barriers. ${ }^{11,15}$ Second-order barriers are more difficult to address; however, overcoming both first- and second-order barriers to achieve desired outcomes is essential if change is to occur. ${ }^{15,16}$

\section{Methods}

\section{Study design}

Our study adopted a qualitative exploratory research design. It was conducted between November 2017 and May 2018.

\section{Setting}

The South East Local Health Integration Network in Ontario covers roughly $25000 \mathrm{~km}^{2}$ and has a population of 500000 (3.6\% of the Ontario population). ${ }^{17}$ Twenty-five percent of the population live in an urban centre, and $45 \%$ live in rural areas. ${ }^{17}$

\section{Recruitment}

Convenience sampling was used for recruitment. We obtained a list of all family physicians practising in the South East Local Health Integration Network by searching postal codes in a publicly available online database (College of Physicians and Surgeons of Ontario, https://www.cpso.on.ca). All identified family physicians were invited to participate via mail, fax or email. Family physicians were eligible if they were willing and able to attend a focus group during the data collection period. Additional focus groups and interviews were scheduled to accommodate family physicians when they were not able to attend prescheduled times. Adult patients were eligible if they had class II obesity and obesity-related comorbidities (e.g., hypertension, diabetes, dyslipidemia) or class III obesity. Referred patients were invited to participate by 1 of the investigators (B.Z.) during scheduled appointments at the Bariatric Centre of Excellence in November 2017. Nonreferred patients were identified by searching the electronic medical record of 1 academic family medicine practice. All adult nonreferred patients were invited to participate by a researcher (J.M.) by telephone or at scheduled appointments.

\section{Data collection}

Semistructured focus group and interview scripts (Appendices 1 and 2, available at www.cmajopen.ca/content/ 7/4/E738/suppl/DC1) were informed by a literature review ${ }^{18}$ to identify previously reported barriers to accessing weightloss interventions and gaps in literature that helped shape questions. Scripts were developed by the research team through multiple discussions and consensus. Scripts were reviewed and revised to include probes for 2 questions that participants thought were unclear (items $9 \mathrm{~b}$ and 10b). Two researchers with expertise in qualitative methods who had no relationship with the study participants conducted the interviews and focus groups. One researcher (C.G.) facilitated the in-person focus groups (duration $90 \mathrm{~min}$ ) with family physicians, and a second researcher (M.M.) wrote notes and summarized main points. One researcher (M.M.) conducted the interviews (duration $35 \mathrm{~min}$ ) with referred and nonreferred patients in person or by telephone. Data collection continued until data saturation was reached (no new information or additional issues emerged, and themes began to repeat). ${ }^{19}$ The focus group discussions and interviews were audiorecorded, transcribed verbatim and deidentified by an external transcriber. One researcher (M.M.) read all transcripts and verified inconsistencies (typographic errors or unclear wording) by listening to the corresponding audiorecordings.

\section{Data analysis}

We adopted an inductive, emergent thematic analysis using open coding in NVivo 12 (QSR International). ${ }^{20,21}$ Members of the research team discussed the codes to ensure consensus and noted key themes to develop a codebook. One researcher (M.M.) coded remaining transcripts, modifying the codebook where necessary and identifying exemplar quotes. Three researchers (B.Z., N.D. and M.M.) grouped the final codes to identify sub- and overarching themes, and conducted comparative thematic analysis ${ }^{20,21}$ to identify relations between groups. The themes were aligned to our theoretical framework. Discussions around personal biases and assumptions were conducted to address reflexivity from the lens of critical self-reflections regarding individual team member's biases, which may have otherwise influenced data collection, analysis and the interpretation of results. ${ }^{22}$

\section{Ethics approval}

Ethics approval was obtained from the Queen's University Health Sciences and Affiliated Teaching Hospitals Research Ethics Board.

\section{Results}

Of the 591 family physicians invited to participate in the focus groups, 43 agreed. Eighteen family physicians who agreed but 
did not participate in the study were lost to follow-up, and 8 declined to participate at a later date. We thus conducted 7 focus groups with 17 family physicians. There were 3 physicians in focus group 1, 4 in focus group 2, 4 in focus group 3, 2 in focus group 4, 1 in focus group 5, 1 in focus group 6 and 2 in focus group 7. Twenty-four referred patients consented; data saturation was achieved after 8 interviews. The electronic medical record search identified 52 nonreferred patients who met our inclusion criteria; 10 were invited and 7 participated. The participants' demographic characteristics are presented in Table 1.

Two themes emerged from our analysis: first-order barriers to change and second-order barriers to change.

\begin{tabular}{|c|c|c|c|}
\hline \multirow[b]{2}{*}{ Characteristic } & \multicolumn{3}{|c|}{ No. (\%) of participants } \\
\hline & $\begin{array}{c}\text { Family } \\
\text { physicians } \\
n=17\end{array}$ & $\begin{array}{l}\text { Referred } \\
\text { patients } \\
n=8\end{array}$ & $\begin{array}{c}\text { Nonreferred } \\
\text { patients } \\
n=7\end{array}$ \\
\hline \multicolumn{4}{|l|}{ Age, yr } \\
\hline $20-29$ & - & $1(12)$ & $0(0)$ \\
\hline 30-39 & - & $2(25)$ & $1(14)$ \\
\hline $40-49$ & - & $1(12)$ & $1(14)$ \\
\hline $50-59$ & - & $2(25)$ & $2(29)$ \\
\hline$\geq 60$ & - & $2(25)$ & $3(43)$ \\
\hline \multicolumn{4}{|l|}{ Practice setting } \\
\hline Urban & $10(59)$ & - & - \\
\hline Rural & $7(41)$ & - & - \\
\hline \multicolumn{4}{|l|}{ Years in practice } \\
\hline$\leq 9$ & $3(18)$ & - & - \\
\hline $10-19$ & $3(18)$ & - & - \\
\hline $20-29$ & $6(35)$ & - & - \\
\hline 30-39 & $3(18)$ & - & - \\
\hline$\geq 40$ & $2(12)$ & - & - \\
\hline \multicolumn{4}{|l|}{ Gender } \\
\hline Male & $5(29)$ & $2(25)$ & $3(43)$ \\
\hline Female & $12(71)$ & $6(75)$ & $4(57)$ \\
\hline \multicolumn{4}{|l|}{ Practice type } \\
\hline $\begin{array}{l}\text { Family Health } \\
\text { Team }\end{array}$ & $6(35)$ & $3(38)$ & $7(100)$ \\
\hline $\begin{array}{l}\text { Other group } \\
\text { practice }\end{array}$ & $6(35)$ & $3(38)$ & $0(0)$ \\
\hline Solo practice & $1(6)$ & $2(25)$ & $0(0)$ \\
\hline $\begin{array}{l}\text { Walk-in clinic or } \\
\text { hospitalist }\end{array}$ & $4(24)$ & $0(0)$ & $0(0)$ \\
\hline \multicolumn{4}{|l|}{ Years with practice } \\
\hline$\leq 4$ & - & $1(12)$ & $3(43)$ \\
\hline $5-9$ & - & $3(38)$ & $4(57)$ \\
\hline $10-14$ & - & $2(25)$ & $0(0)$ \\
\hline$\geq 20$ & - & $2(25)$ & $0(0)$ \\
\hline
\end{tabular}

\section{First-order barriers to change}

Resource supports, logistics and lack of knowledge were the subthemes identified as first-order barriers. Table 2 includes representative quotes.

\section{Resource supports}

Having supportive local and community resources was a major facilitator for family physicians in accessing weight-loss interventions for patients with obesity. This was especially true for those working in interprofessional models of primary care. Conversely, family physicians without ready access to group or community programming, specialists or allied health care professionals identified lack of resources as a major barrier, especially for those in solo practice or rural locations. Similarly, patients in rural areas suggested that limited community resources was a barrier to accessing weight-loss interventions. This was not a barrier for patients in urban areas.

\section{Logistics}

Lack of time, costs and geographic location were important barriers to accessing weight-loss interventions. All groups perceived lack of time for family physicians as a barrier. Cost was also a barrier for referred and nonreferred patients to access support services (e.g., nutritional programs, private dietitians), especially for those in rural areas where these resources were not available. Most family physicians stated that access to weight-loss interventions was facilitated by having financial means for private services and medications; however, many patients were not able to afford these treatments. Distance from the Bariatric Centre of Excellence and expensive travel costs were also reported to be a barrier to accessing weight-loss interventions for patients who lived in rural or remote areas.

\section{Lack of knowledge}

Referred and nonreferred patients believed that family physicians' lack of knowledge was a key barrier to accessing weight-loss interventions. They felt their family physician did not possess the knowledge required to discuss all available weight-loss intervention options. Referred patients overwhelmingly perceived that their family physician lacked knowledge about bariatric surgery. Family physicians also acknowledged their dearth of knowledge about bariatric surgery, primarily regarding postsurgical complications and follow-up. Some family physicians struggled with their role as motivator and believed they lacked knowledge and education about how to effectively encourage patients to make necessary lifestyle changes. Family physicians were also unsure and uncomfortable about how to sensitively discuss weight-loss interventions with patients unless the discussion was associated with an obesity-related comorbidity. This was confirmed by nonreferred patients, the majority of whom stated that they had never discussed surgical weight-loss interventions with their family physician. As well, family physicians admitted that they did not know how or where to refer their patients for medical and surgical weight-loss interventions. Finally, many family physicians suggested that a patient's lack 
Table 2: Selected quotes for theme 1: first-order barriers to change

\begin{tabular}{|c|c|}
\hline Subtheme & Representative quote \\
\hline \multirow[t]{4}{*}{$\begin{array}{l}\text { Resource } \\
\text { supports }\end{array}$} & $\begin{array}{l}\text { The clinics that I am involved with, they are pretty well equipped, to be honest. ... All the ones that I } \\
\text { have worked in have specific weight-loss programs. At [location], it is "healthy weight, healthy you." } \\
\text { In [alternative location] family health team, it is the metabolic change program. So, the programs } \\
\text { are available, and I feel we are well supported in that way. (family physician 10) }\end{array}$ \\
\hline & $\begin{array}{l}\text { We don't have anyone to turn to or to direct people to. Some people come in and are quite } \\
\text { motivated. They want to meet with the dietitian, and they know that their friend who is a patient at a } \\
\text { [family health] team has met with a dietitian at their family doctor's office. So why can't that happen } \\
\text { [for them]? It is unfair, mostly for the patient. (family physician 2) }\end{array}$ \\
\hline & $\begin{array}{l}\text { Plus she sent me to the ... nutritional program at the hospital.... Each level that I wanted to take or } \\
\text { each different ... platform that they were supposed to deliver that I wanted ... they said "Oh, right } \\
\text { now we're not doing that one." (nonreferred patient } 6 \text { ) }\end{array}$ \\
\hline & $\begin{array}{l}\text { I was doing exercise at the pool.... My wife and I were going for about } 5 \text { or } 6 \text { years and we were } \\
\text { doing aquafit. But the town closed the pool. And when that happened, that exacerbated my weight } \\
\text { issues and my blood pressure issues. (referred patient 2) }\end{array}$ \\
\hline \multirow[t]{7}{*}{ Logistics } & $\begin{array}{l}\text { I find the other barrier is lack of time. If I could sit with them [patients] and do a motivational speech } \\
\text { to them every week, I bet you I could help them stay on plan. But I just don't have that kind of time, } \\
\text { and I don't have someone in my office who does.... And certainly, the cost ... liraglutide is horribly } \\
\text { expensive. So, you have to be well [off] to afford it. (family physician 5) }\end{array}$ \\
\hline & $\begin{array}{l}\text { I only have so much time, and then she [family physician] is off to the next appointment. I don't think } \\
\text { the time necessary is afforded for the patient. I feel like I am in, I talk about whatever is bothering } \\
\text { me, "Here is a prescription to take care of it" and off to the next patient. (referred patient 6) }\end{array}$ \\
\hline & $\begin{array}{l}\text { The doctor's not available. The clinic's not open. They work limited hours, and if you want an } \\
\text { appointment you have to wait an inordinately long time to get one. (nonreferred patient 1) }\end{array}$ \\
\hline & I have so few people who will go to a private dietitian because of the cost. (family physician 1) \\
\hline & $\begin{array}{l}\text { I went to Herbal Magic and that was expensive. I did lose my weight, but I couldn't afford to keep } \\
\text { that up. (referred patient 3) }\end{array}$ \\
\hline & $\begin{array}{l}\text { Even just basic things like transport to the bariatric program, for instance, is very costly, especially } \\
\text { if you are morbidly obese because you require more expensive patient transfer than just taking the } \\
\text { access bus, for instance. (family physician } 4 \text { ) }\end{array}$ \\
\hline & $\begin{array}{l}\text { Consultation with specialists - is there a specialist around? I would be happy to refer. I don't know } \\
\text { any. (family physician 13) }\end{array}$ \\
\hline \multirow[t]{8}{*}{$\begin{array}{l}\text { Lack of } \\
\text { knowledge }\end{array}$} & $\begin{array}{l}\text { I wish they [family physicians] were more knowledgeable on different options. They are, like, "Oh, } \\
\text { you have weight issues, then go see a dietitian." "Oh, you still have weight issues, then exercise." I } \\
\text { could literally search that on Google. There is no in-depth.... That is why I say I think doctors } \\
\text { should be educated on that enough to sit down with the person and give [him or her] that } \\
\text { information instead of saving it for when you get into the program. (referred patient 4) }\end{array}$ \\
\hline & $\begin{array}{l}\text { She [family physician] didn't really know about the bariatric clinic. So basically I kind of told her and } \\
\text { then she looked into it. .... So, I mean, she did do the research after she found out about it. } \\
\text { (nonreferred patient } 4 \text { ) }\end{array}$ \\
\hline & $\begin{array}{l}\text { But managing [patients] afterwards? It is, like, "You have an issue? Go to your surgeon." ... All } \\
\text { these wonderful vitamins that they are on, and they get blood work done every month. And there is } \\
\text { this dumping syndrome and postsurgical hyporeactive glycemia. And I am, like, "I don't know what } \\
\text { is going on." ... When you're looking at a population that is marginalized financially, marginalized } \\
\text { from an educational perspective ... you're dealing with a knowledge deficit. (family physician 11) }\end{array}$ \\
\hline & $\begin{array}{l}\text { I am thinking, too, for myself. Physicians are expected to be a motivator. ... How am I going to talk } \\
\text { about the weight or the diabetes? I have never had any training to be able to put myself in that } \\
\text { person's shoes and understand stuff. (family physician 8) }\end{array}$ \\
\hline & $\begin{array}{l}\text { I suppose that if [patients] were morbidly obese, I might bring up surgery at some point, although I } \\
\text { find that a very sensitive topic. People feel like they're a lost cause. (family physician 15) }\end{array}$ \\
\hline & $\begin{array}{l}\text { With the bariatric surgery, the weight-loss surgery ... maybe if the doctor could mention more about } \\
\text { how it is done and if there will be any side effects, how long the recovery time will be, whether it's } \\
\text { months or years. It might be useful information. (nonreferred patient } 07 \text { ) }\end{array}$ \\
\hline & $\begin{array}{l}\text { [I don't know] the resources in the community. To be honest, other than knowing what is in my } \\
\text { hospital, I don't really know where to refer people. (family physician 10) }\end{array}$ \\
\hline & $\begin{array}{l}\text { Some of them [patients] don't acknowledge that their weight is a problem at all. And they're quite } \\
\text { comfortable with their weight being what it is and don't see it as an issue, even though they may } \\
\text { have comorbidities. (family physician 12) }\end{array}$ \\
\hline
\end{tabular}




\begin{tabular}{|c|c|}
\hline Subtheme & Representative quote \\
\hline \multirow[t]{3}{*}{$\begin{array}{l}\text { Root causes of } \\
\text { obesity }\end{array}$} & $\begin{array}{l}\text { My doctor said ... "You've got to give up everything white." ... Like pasta and rice and } \\
\text { bread. And I said "You're killing me here." That has always been my diet, growing up and } \\
\text { everything. (nonreferred patient 2) }\end{array}$ \\
\hline & $\begin{array}{l}\text { Healthy eating ... was actually the hardest for me to do because I am a food addict. I } \\
\text { have to be so careful. It is almost like I have to abstain from eating foods that trigger. } \\
\text { (referred patient } 7 \text { ) }\end{array}$ \\
\hline & $\begin{array}{l}\text { The thing that I struggle with most is that their root causes of obesity are outside of spirit } \\
\text { of control and influence. So, things like access to healthy food, sedentary lifestyle, the } \\
\text { built environment ... those are all things that have led us to where we are. (family } \\
\text { physician 6) }\end{array}$ \\
\hline \multirow[t]{6}{*}{ Motivation } & $\begin{array}{l}\text { Recently ... I had a patient and she was motivated because she wanted to have [in vitro } \\
\text { fertilization] and was told she had to lose } 150 \text { to } 200 \text { pounds [68-91 kg]... She has had } \\
\text { great success, but again it is because she has a goal that she wants to get to so that she } \\
\text { can finally have [in vitro fertilization]. (family physician 2) }\end{array}$ \\
\hline & $\begin{array}{l}\text { I would say that most people don't want to change, to be honest. It doesn't matter what } \\
\text { resources you have available. If you have this wonderful multidisciplinary team with a } \\
\text { dietitian and social workers and everything ... a lot of people are just not ready to } \\
\text { change yet. (family physician } 8 \text { ) }\end{array}$ \\
\hline & $\begin{array}{l}\text { He's [physician] pointed me in all the right directions, now it's just up to me to do it. It's } \\
\text { an everyday battle. (nonreferred patient } 5 \text { ) }\end{array}$ \\
\hline & $\begin{array}{l}\text { Maybe this [bariatric surgery] will make me change the way I eat everything and exercise } \\
\text { more and stuff like that. It was the motivation to have that good kick in the butt kind of } \\
\text { thing to get you going to lose the weight. (referred patient 5) }\end{array}$ \\
\hline & $\begin{array}{l}\text { I thought that it would be a proactive thing that I could do to lose weight and to control } \\
\text { my diabetes. (referred patient 2) }\end{array}$ \\
\hline & $\begin{array}{l}\text { To be healthier and to be able to control the weight areas, because l'm not really sure } \\
\text { just with my weight just how many [comorbid conditions] it is controlling, you know. } \\
\text { (nonreferred patient 2) }\end{array}$ \\
\hline \multirow[t]{3}{*}{$\begin{array}{l}\text { Perceptions of } \\
\text { bariatric surgery }\end{array}$} & $\begin{array}{l}\text { Of course, you will lose the weight for sure, but you end up with all sorts of possible } \\
\text { complications, plus it's not reversible.... It has a lot of risks, I think. I'm just not } \\
\text { convinced.... Once you're convinced yourself, then you can recommend, and so until } \\
\text { they [patients] have tried nonsurgical measures, I would not recommend surgery. I just } \\
\text { feel it's like suggesting something that I think is harmful. (family physician 13) }\end{array}$ \\
\hline & $\begin{array}{l}\text { I kind of wish my doctor had encouraged me a while back regarding surgery. It is almost } \\
\text { like surgery is taboo or it is not something that is encouraged. They make it feel like it is } \\
\text { the last resort. (referred patient } 6 \text { ) }\end{array}$ \\
\hline & $\begin{array}{l}\text { I think if I ... [changed] my diet and my lifestyle with the exercising and everything, } \\
\text { and if I kept gaining weight, then it wouldn't be just being lazy - then it [bariatric } \\
\text { surgery] might be an option for me. But with what l'm doing right now and the } \\
\text { improvement I'm seeing, most likely I wouldn't say yes to it at the very moment. } \\
\text { (nonreferred patient 7) }\end{array}$ \\
\hline
\end{tabular}

of education about nutrition and the medical implications of obesity was a major barrier to provision of quality care.

\section{Second-order barriers to change}

We identified 3 subthemes as second-order barriers to change: root causes of obesity, motivation and perceptions of bariatric surgery. Table 3 includes representative quotes.

\section{Root causes of obesity}

The participant groups expressed varied opinions about the root causes of obesity. The referred and nonreferred patients believed that their obesity stemmed from a general lack of self-control and a preference for processed and junk foods. They were certain that obesity was a consequence of lifestyle choices and blamed themselves for their weight issues. Several referred patients stated that they had a food addiction: an inability to stop eating. In contrast, family physicians held a broader view, believing it was primarily the societal influence on obesity that has lead to the current epidemic. They identified factors such as targeted advertising of processed foods (especially to children), lack of education about healthy eating habits, unaddressed mental health issues and high costs of healthy foods as contributors.

\section{Motivation}

Motivation emerged as a second-order barrier to change in all participant groups. Family physicians noted that treating highly motivated patients was a facilitator in initiating weightloss interventions. They believed such patients were the most successful in losing weight, were goal-oriented, and were most 
often motivated by the desire to get pregnant or treat obesityrelated comorbidities. Conversely, family physicians found that lack of readiness for health behaviour change was a barrier to accessing weight-loss interventions for patients with obesity. Nonreferred patients agreed, stating that, even when their doctor gave advice, it was ultimately up to them to make changes. Family physicians were motivated to refer patients for surgical weight-loss interventions only when patients suggested or requested it. Motivation to seek surgical weight-loss interventions for referred patients included a desire to lose weight or control food intake, or have surgery initiate the weight-loss process. Referred patients were motivated to improve overall health and treat symptoms of obesity-related comorbidities. Nonreferred patients also cited alleviating comorbidities as the main motivator for considering a surgical weight-loss intervention.

\section{Perceptions of bariatric surgery}

Although family physicians perceived bariatric surgery to be effective for weight loss and resolving obesity-related comorbidities, most viewed it as high risk and associated with major postoperative short- and long-term complications. It was seen as a last resort after unsuccessful attempts at all other weightloss interventions. Referred patients confirmed this perception, with most noting they explicitly asked for a referral for surgery from their family physicians. Referred patients stated that their family physician did not suggest surgery as a viable option but wished it had been a part of their initial discussion and health care plan. Despite qualifying for surgical weightloss interventions, all nonreferred patients stated that their family physician did not discuss it as a treatment option. They, too, believed that a surgical weight-loss intervention was a final option and would be considered only if other treatments remained ineffective.

\section{Interpretation}

We identified the following barriers to accessing weight-loss interventions for patients with class II or III obesity: resource supports, logistics, lack of knowledge, root causes of obesity, motivation and perceptions of bariatric surgery. We identified contrasting views from family physicians and patients about the root causes of obesity. Family physicians were aware of multiple extrinsic and intrinsic causes of obesity, including behavioural, social, economic and psychologic, whereas patients with obesity believed that intrinsic causes were the dominant reasons for their obesity. The association among socioeconomic status, lack of physical activity, unhealthy food choices and obesity is well documented in the literature; ${ }^{23-25}$ however, patients seem to be unaware of this complex interplay among environmental, behavioural, economic and psychologic factors. ${ }^{26}$ Family physicians and other allied health care professionals should take the opportunity to educate patients about risk factors for obesity, which may help eliminate the pervasive misconception that obesity is a self-induced disease.

We identified cost as a barrier to accessing weight-loss interventions for patients with obesity. Increased distance travelled by patients to access care has been shown to be associated with less adherence to follow-up, ${ }^{27,28}$ reduced long-term survival $^{27}$ and increased likelihood of emergency department visits following bariatric surgery. ${ }^{29}$ Supplements, which are required after bariatric surgery, are rarely covered by health insurance plans, which can be a prohibitive barrier to accessing surgical weight-loss interventions for economically disadvantaged patients. This barrier to accessing weight-loss interventions will require systemic changes to the current health care system and insurance coverage.

Regarding lack of motivation for change in patients with obesity as a barrier to accessing weight-loss intervention, continuing professional development for family physicians centred on motivational interviewing and effective communication strategies would assist them in overcoming this barrier. ${ }^{30,31} \mathrm{We}$ also identified family physicians' lack of knowledge and misconceptions about contemporary bariatric surgery as a barrier to accessing surgical weight-loss interventions. Similar results were noted in a recent systematic review of factors that influence primary care providers' referral for bariatric surgery. ${ }^{18}$ We have also previously shown that only $6.7 \%$ of all eligible patients with class II or III obesity were referred for weight-loss interventions in 1 region of Ontario. ${ }^{32}$

Like other authors, ${ }^{27,33}$ we suggest addressing identified barriers to accessing weight-loss interventions not only by focusing on continuing professional development efforts to improve family physicians' overall care of patients with obesity and their referral practices but also by improving access for patients to supportive local and community resources, and for family physicians to interprofessional teams. As part of an interprofessional approach to weight-loss interventions, allied health care professionals should address the multiple factors associated with obesity holistically. Integration of family physicians into interprofessional health care teams may help overcome some of first- and second-order barriers to accessing weight-loss interventions that we have identified.

\section{Limitations}

We conducted our study in 1 region of Ontario, and patients were recruited from a bariatric centre of excellence and 1 family practice, which may limit the generalizability of our findings to other contexts. Women were disproportionately represented $(75 \%)$ in the referred patient group; however, this is consistent with the overall referral patterns for weight-loss interventions in our region ${ }^{32}$ and across Canada. ${ }^{4} \mathrm{We}$ did not use a tool such as the Edmonton Obesity Staging System ${ }^{34}$ to further classify the severity of obesity for the patient participants. As such, it is possible that there was a difference in barriers experienced by participants with class II or III obesity in relation to metabolic, mechanical and mental health sequelae of obesity that was not identified in our study. In addition, geographic limitations and physician availability led to smaller focus group sizes (1-3 participants), whereas 4-12 participants are recommended to optimize group dynamics and elicit broad discussion; ${ }^{35}$ this may have limited our findings. Last, there may have been selection bias in our voluntary and 
convenience sampling, which may have resulted in selecting those interested in access to weight-loss interventions.

\section{Conclusion}

It is important to address first- and second-order barriers to accessing medical and surgical weight-loss interventions to help ensure effective treatment for patients with obesity and related comorbidities. As a next step, we plan to develop, implement and evaluate continuing professional development programs that address the barriers identified in our study.

\section{References}

1. Mokdad AH, Ford ES, Bowman BA, et al. Prevalence of obesity, diabetes, and obesity-related health risk factors, 2001. 7AMA 2003;289:76-9.

2. Dhabuwala A, Canna RJ, Stubbs RS. Improvement in co-morbidities following weight loss from gastric bypass surgery. Obes Surg 2000;10:428-35.

3. Fortin MMR, Brown C, Ball GD, et al. Weight management in Canada: an environmental scan of health services for adults with obesity. BMC Health Serv Res 2014;14:69.

4. Report card on access to obesity treatment for adults in Canada 2019. Edmonton: Obesity Canada; 2019.

5. Rubino F, Nathan DM, Eckel RH, et al. Metabolic surgery in the treatment algorithm for type 2 diabetes: a joint statement by international diabetes organizations. Diabetes Care 2016;39:861-77.

6. Chawla AS, Hsiao CW, Romney MC, et al. Gap between evidence and patient access: policy implications for bariatric and metabolic surgery in the treatment of obesity and its complications. Pharmacoeconomics 2015;33:629-41.

7. Perlman SE, Reinhold RB, Nadzam GS. How do family practitioners perceive surgery for the morbidly obese? Surg Obes Relat Dis 2007;3:428-33.

8. Auspitz M, Cleghorn MC, Azin A, et al. Knowledge and perception of bariatric surgery among primary care physicians: a survey of family doctors in Ontario. Obes Surg 2016;26:2022-8.

9. Fullan M. Change forces: probing the depths of educational reform. School Development and the Management of Change series 10. Bristol (PA): Falmer Press, Taylor \& Francis; 1994.

10. Fullan M. The new meaning of educational change. 4th ed. New York: Teachers College Press; 2007.

11. Fullan MG, Stiegelbauer S. The new meaning of educational change. 2nd ed. New York: Teachers College Press; 1991.

12. Spillane JP, Reiser BJ, Reimer T. Policy implementation and cognition: reframing and refocusing implementation research. Rev Educ Res 2002; 72:387-431.

13. Ertmer PA. Addressing first- and second-order barriers to change: strategies for technology integration. Educ Technol Res Dev 1999:47:47-61.

14. Fullan M, Pomfret A. Research on curriculum and instruction implementation. Rev Educ Res 1977;47:335-97.

15. Rubin JK, Hinrichs-Krapels S, Hesketh R, et al. Identifying barriers to appropriate use of metabolic/bariatric surgery for type 2 diabetes treatment: policy lab results. Diabetes Care 2016;39:954-63.

16. McLaughlin MW. The RAND change agent study: ten years later. In: Odden AR, editor. Education policy implementation. Albany (NY): SUNY Press; 1991: $143-55$.

17. Integrated health service plan 2016-2019: Appendix: B. Regional capacity analysis and projections (ReCAP). Belleville (ON): South East Local Health Integration Network; 2016. Available: www.southeastlhin.on.ca/ /media/sites/se/UploadedFiles/ IHSP/IHSP4\%202016-2019/IHSP4\%20ReCAP-Appendix\%20B.pdf?la=en (accessed 2019 Mar. 5).

18. Zevin B, Sivapalan N, Chan L, et al. Factors influencing family physicians' referral for bariatric surgery: a systematic review. Can Fam Physician. In press.

19. Kerr C, Nixon A, Wild D. Assessing and demonstrating data saturation in qualitative inquiry supporting patient-reported outcomes research. Expert Rev Pharmacoecon Outcomes Res 2010;10:269-81.
20. Creswell JW, Creswell JD. Research design: qualitative, quantitative, and mixed methods approaches. 5th ed. Thousand Oaks (CA): Sage Publications; 2017

21. Saldaña J. The coding manual for qualitative researchers. 3rd ed. Thousand Oaks (CA): Sage Publications; 2015.

22. Berger R. Now I see it, now I don't: researcher's position and reflexivity in qualitative research. Qual Res 2015;15:219-34.

23. McLaren L. Socioeconomic status and obesity. Epidemiol Rev 2007;29:29-48.

24. Biro S, Williamson T, Leggett JA, et al. Utility of linking primary care electronic medical records with Canadian census data to study the determinants of chronic disease: an example based on socioeconomic status and obesity. BMC Med Inform Decis Mak 2016;16:32.

25. Wardle J, Steptoe A. Socioeconomic differences in attitudes and beliefs about healthy lifestyles. 7 Epidemiol Community Health 2003;57:440-3.

26. Puhl RM, Moss-Racusin CA, Schwartz MB, et al. Weight stigmatization and bias reduction: perspectives of overweight and obese adults. Health Educ Res 2008;23:347-58.

27. Kirk SF, Penney TL. The role of health systems in obesity management and prevention: problems and paradigm shifts. Curr Obes Rep 2013;2:315-9.

28. Larjani S, Spivak I, Hao Guo M, et al. Preoperative predictors of adherence to multidisciplinary follow-up care postbariatric surgery. Surg Obes Relat Dis 2016; 12:350-6.

29. Telem DA, Yang J, Altieri M, et al. Rates and risk factors for unplanned emergency department utilization and hospital readmission following bariatric surgery. Ann Surg 2016;263:956-60.

30. Resnicow K, McMaster F. Motivational interviewing: moving from why to how with autonomy support. Int 7 Behav Nutr Phys Act 2012;9:19.

31. Ekong G, Kavookjian J. Motivational interviewing and outcomes in adults with type 2 diabetes: a systematic review. Patient Educ Couns 2016;99:944-52.

32. Barber D, Morkem R, Dalgarno N, et al. A retrospective cohort study examining patients eligible for bariatric surgery and those being referred in south eastern Ontario. Can Fam Physician. In press.

33. Auspitz M, Cleghorn MC, Azin A, et al. Knowledge and perception of bariatric surgery among primary care physicians: a survey of family doctors in Ontario. Obes Surg 2016;26:2022-8.

34. Gill RS, Karmali S, Sharma AM. The potential role of the Edmonton Obesity Staging System in determining indications for bariatric surgery. Obes Surg 2011;21:1947-9.

35. Carlsen B, Glenton C. What about N? A methodological study of sample-size reporting in focus group studies. BMC Med Res Methodol 2011;11:26.

Affiliations: Department of Surgery (Zevin), Queen's University; Office of Professional Development and Educational Scholarship (Dalgarno), Faculty of Health Sciences, Queen's University; Department of Biomedical and Molecular Science (Dalgarno), Queen's University; Centre for Studies in Primary Care (Martin, Grady, Matusinec, Birtwhistle, Morkem, Barber), Department of Family Medicine, Queen's University; Department of Medicine (Houlden), Queen's University; Department of Physical Medicine and Rehabilitation (Smith), Queen's University, Kingston, Ont.

Contributors: Boris Zevin and David Barber conceived the study. Boris Zevin, Nancy Dalgarno, Mary Martin, David Barber and Jacob Matusinec contributed equally to the data analysis and interpretation. All of the authors contributed equally to the project design and data collection tools, drafted the manuscript, revised the manuscript critically for important intellectual content, approved the final version to be published and agreed to be accountable for all aspects of the work.

Funding: This research was funded by Medtronic.

Disclaimer: Medtronic had no role in the study's design, conduct or reporting.

Supplemental information: For reviewer comments and the original submission of this manuscript, please see www.cmajopen.ca/content/7/4/ E738/suppl/DC1. 